\title{
Less Invasive Surfactant Administration in Preterm Infants with Respiratory Distress Syndrome
}

\author{
Alia Halim, Haider Shirazi, Sadia Riaz, Syeda Shireen Gul and Wahid Ali
}

\begin{abstract}
Objective: To compare the need of mechanical ventilation between LISA (less invasive surfactant administration) method and conventional INSURE method (INtubation SURfactant administration and Extubation) in spontaneously breathing preterm infants with respiratory distress syndrome (RDS).

Study Design: An experimental study.

Place and Duration of Study: Department of Neonatology, PIMS, Islamabad, from April to December 2017.

Methodology: A total of 100 preterm infants $<34$ weeks gestation, on nasal CPAP requiring fraction of inspire oxygen $\left(\mathrm{FiO}_{2}\right)>0.4$, with respiratory distress syndrome (RDS) were included in the study and divided randomly into two groups, 50 each.

Results: There were $28(56 \%)$ males in LISA and $31(62 \%)$ in the INSURE group. Median birth weight was 1300 grams (IQR 600) in LISA, while 1400 grams (IQR 400) in INSURE infants. C-section rate was $52 \%(n=26)$ and $48 \%(n=24)$ in LISA and INSURE, respectively. Pre-natal steroids were given to 38 patients $(76 \%)$ in LISA and 30 patients $(60 \%)$ in INSURE group. LISA patients had significantly less need of mechanical ventilation with $p$-value $<0.05\{30 \%(n=15)$ vs. $60 \%(n=30)$. The median duration of mechanical ventilation was 40 hours (IQR 75) and 71 hours (IQR 62) in LISA and INSURE, respectively. Similarly, median $\mathrm{FiO}_{2}$ reduction was 30 (IQR 30) in LISA group and it was 25 (IQR 10) in INSURE group, with $p$-value $<0.05$. There was no significant difference in mortality, hospital stay and complications.

Conclusion: LISA technique was safe, non-invasive approach of surfactant administration, with reduced need of mechanical ventilation rate and duration.
\end{abstract}

Key Words: Less invasive surfactant administration (LISA), Respiratory distress syndrome (RDS), Non-invasive ventilation, Intubation surfactant administration and extubation (INSURE), Surfactant.

\section{INTRODUCTION}

Respiratory distress syndrome (RDS) remains one of the major reasons of neonatal mortality and morbidity in preterm infants. ${ }^{1}$ It is caused by surfactant deficiency leading to atelectasis and ventilation perfusion (V/Q) mismatch. It presents with tachypnea, cyanosis, retractions, and grunting (due to partial closure of glottis). Surfactant reduces the surface tension of alveoli, thereby preventing alveolar collapse during expiratory phase with improved lung compliance. The use of exogenous surfactant therapy and ventilation has improved the outcome of preterm neonates with RDS since 1990s. ${ }^{1}$ Nasal continuous positive airway pressure (nCPAP) is increasingly used for RDS to reduce acute lung trauma. Surfactant therapy combined with nCPAP for alveolar recruitment has revolutionized the management of RDS.1,2

Surfactant is conventionally being given via endotracheal tube. Neonatal units are now adopting a gentle

Department of Neonatology, Children Hospital PIMS,

Islamabad, Pakistan

Correspondence: Dr. Alia Halim, Department of Neonatology,

Children Hospital PIMS, Islamabad, Pakistan

E-mail:dr.aliahalim@gmail.com

Received: March 10, 2018; Accepted: November 10, 2018 and non-invasive method for respiratory support in preterm infants in an attempt to avoid the complications of endotracheal intubation. Verder et al. introduced the INSURE technique, named after the three key stages in the procedure: INtubation, SURfactant administration followed by quick Extubation to reduce acute lung injury. 1,2 This new technique aimed to avoid mechanical ventilation. Infants were provided nCPAP for respiratory support after the procedure. This approach reduces the alveolar injury compared to mechanical ventilation and the incidence of bronchopulmonary dysplasia (BPD). 3,4 Though this method is considered safe, but still requires brief period of positive airway pressure ventilation after administration of surfactant.

INSURE method was further modified to avoid even this brief positive pressure ventilation. Kribs et al. used minimally invasive surfactant therapy (MIST), also called less invasive surfactant administration (LISA) with the aim to prevent intubation for surfactant delivery. ${ }^{5}$ This technique ensures continuous uninterrupted nCPAP throughout the entire procedure; hence, temporary loss of functional lung capacity and atelectasis during the intubation can be prevented. Surfactant is administered into the trachea by direct laryngoscopy, via a thin tube (4-5 FG feeding tube) through the vocal cords, while the infant remains on nCPAP. After surfactant administration, the tube is immediately removed. LISA can avoid the 
need for sedation and tracheal intubation; and has shown promising results with reduced need for mechanical ventilation, improved oxygenation, decreased duration of ventilation. ${ }^{5-7}$

Currently, the literature regarding LISA technique among preterm infants is limited. It may have a prominent role in future care of preterm infants with respiratory distress. In Pakistan, most of the neonatal units are using nCPAP, surfactant and mechanical ventilation in management of RDS. There is no published data from Pakistan on this technique.

The aim of this study was to compare results in infants receiving surfactant with LISA technique to those treated with INSURE technique.

\section{METHODOLOGY}

This experimental study was conducted in Neonatal Unit of Pakistan Institute of Medical Sciences (PIMS), Islamabad, from April till December 2017. Approval was taken from Institutional Ethical Review Board. A written informed consent was taken from parents for participation in the study.

Serial numbers from 1-100 were randomized divided into two groups using a web-based randomization tool (www.randomizer.org). Subjects were assigned the treatment group in order of their enrolment number. All the spontaneously breathing preterm neonates born in $\mathrm{MCH}$ (Mother and Child Health) Center, PIMS at $\leq 34$ weeks of gestation, who developed RDS, were included in the study. Both groups were placed on nCPAP with $\mathrm{FiO}_{2}$ adjusted to maintain $\mathrm{O}_{2}$ saturations of $88-92 \%$. They were given surfactant, if they needed $\mathrm{FiO}_{2}$ of $>0.4$ during first 12 hours of life. All those premature neonates having major congenital malformations and those who required intubation for resuscitation at birth were excluded from study population.

RDS was diagnosed on the basis of prematurity, tachypnea with respiratory rate $>60 /$ minute, subcostal or intercostal chest recession, grunting, nasal flaring, and cyanosis. Radiological findings of RDS were bilateral diffuse reticular granular (ground glass) appearance, air bronchograms and poor lung expansion. They were placed initially on nCPAP to maintain $\mathrm{SpO}_{2}$. Sample size was calculated according to WHO sample size calculator. The proportion of population requiring intubation in the LISA group was assumed to be $43 \%$, while the proportion of population requiring intubation in INSURE group was $73 \% .8$ Using sample size calculator, the final estimated sample for a study with $80 \%$ power and $95 \%$ confidence interval, was 43 patients for each group. Fifty patients were included in each group to cater for dropouts.

All the babies enrolled in study were initially placed on nCPAP (infant flow driver device, Care Fusion, Sandiego,
CA). Respiratory support was provided with an initial pressure of 5 to $7 \mathrm{~cm}$ of water and $\mathrm{FiO}_{2}$ of 0.3 . They were randomized into two groups for the technique of surfactant administration, LISA or INSURE. In LISA group, surfactant was administered at a dose of $100 \mathrm{mg} / \mathrm{Kg}$ of Survanta with the help of size $6 \mathrm{Fr}$ nasogastric tube. Upper respiratory tract was visualized with laryngoscope and the catheter was passed 1-2 cm past the vocal cords. Surfactant was delivered within 1-3 minutes in small aliquots, while the infant continued breathing with nCPAP, during and after the procedure. If catheterization was not possible in 20-30 seconds, the procedure was discontinued and attempted once again, when the baby was stable. The tracheal catheter was removed immediately after the procedure. Infant's heart rate and $\mathrm{SpO}_{2}$ were monitored during the procedure via pulse oximetry. $\mathrm{FiO}_{2}$ was adjusted to attain a target $\mathrm{SpO}_{2}$. Subsequent dose of surfactant was given, if infants met inclusion criteria again in first 12-24 hours. If infant's requirement of $\mathrm{FiO}_{2}>0.4$ or severe work of breathing, or persistent apneas were present then the patients were mechanically ventilated. This procedure was performed by senior neonatologists themselves who were experienced in carrying out intratracheal catheterization.

In the second group, i.e. the INSURE group, the infants were intubated and surfactant was administered successfully in 2-3 aliquots with endotracheal tube with same dose as in LISA group, while they received positive pressure ventilation via T-piece resuscitaire. After a brief period of positive pressure ventilation for 15-20 minutes, the endotracheal was removed and the infants were placed on nCPAP. The criteria for subsequent dose of surfactant and mechanical ventilation were the same as in LISA group. All the data variables were recorded for both groups on a specifically designed proforma.

Data was entered and analyzed through SPSS version 21. Mean $\pm S D$ (standard deviation values) were calculated for quantitative data, following normality. Median along with Interquartile range (IQR) was calculated the quantitative data which was not following normal distribution. Frequencies and percentages were presented for categorical data. Chi-square test along with Fischer exact test were applied for qualitative data, and independent sample t-test was used for quantitative data. The quantitative data was tested for normality by Kolmogorov-Smirnov test and the variables which were not following normality were compared with MannWhitney U-test. P-value $<0.05$ was deemed significant.

\section{RESULTS}

During the study period, total admissions in the neonatal unit were 1188. A total of 148 preterm born at $\leq 34$ weeks of gestation developed RDS. Among them, 100 
spontaneously breathing babies, who fulfilled our inclusion criteria, were enrolled in study group, each comprising 50 newborns. The demographic data showed no significant difference in both groups. There were $28(56 \%)$ male newborns in LISA group and 31 $(62 \%)$ male newborns in INSURE group ( $p$-value 0.542 ). The median birth weight of babies in LISA group was 1300 grams, IQR 600 grams; and in INSURE group, the median birth weight was 1400 grams, IQR 400 grams with no significant difference in both groups ( $p$-value $0.204)$. Cesarean section frequency was $52 \% n=26$ in LISA, while $48 \% \mathrm{n}=24$ in INSURE group. Demographics are shown in Table I.

Table I: Demographic and clinical characteristics of both groups.

\begin{tabular}{|c|c|c|c|}
\hline & LISA $n=50$ & INSURE $n=50$ & $p$-value \\
\hline Male gender $\mathrm{n}(\%)$ & $28(56 \%)$ & $31(62 \%)$ & 0.542 \\
\hline Female gender $\mathrm{n}(\%)$ & $22(44 \%)$ & $19(30 \%)$ & \\
\hline \multicolumn{4}{|l|}{ Gestational age $\mathrm{n}(\%)$} \\
\hline 32-34 weeks & $26(52 \%)$ & $24(48 \%)$ & 0.87 \\
\hline $30-31+6$ weeks & $11(22 \%)$ & $14(28.6 \%)$ & \\
\hline $28-29+6$ weeks & $8(16 \%)$ & $6(12.2 \%)$ & \\
\hline$<28$ weeks & $5(10 \%)$ & $5(10.2 \%)$ & \\
\hline $\begin{array}{l}\text { Birth weight grams, } \\
\text { median (IQR) }\end{array}$ & $1300(600)$ & $1400(400)$ & 0.204 \\
\hline C-Section n (\%) & $26(52 \%)$ & $24(48 \%)$ & 0.689 \\
\hline SVD n (\%) & $24(48 \%)$ & $26(52 \%)$ & \\
\hline \multicolumn{4}{|l|}{ Prenatal steroids $\mathrm{n}(\%)$} \\
\hline Yes n (\%) & $38(76 \%)$ & $30(60 \%)$ & 0.086 \\
\hline No n (\%) & $12(24 \%)$ & $20(40 \%)$ & \\
\hline $\begin{array}{l}\text { Age at the time of } \\
\text { procedure in hours, } \\
\text { median (IQR) }\end{array}$ & $4.0(6.0)$ & $6.0(5.25)$ & 0.039 \\
\hline
\end{tabular}

The catheter was passed properly and surfactant was delivered successfully in all the patients in LISA group. Only one patient needed a second attempt of intratracheal catheterization. None of them required intubation for surfactant administration. Similarly, surfactant was given successfully to all patients in INSURE group via endotracheal tube. The results of the neonatal outcomes between the two groups are shown in Table II.

$\mathrm{FiO}_{2}$ reduction was significantly higher in LISA group $(p=0.031)$. The need of invasive mechanical ventilation was significantly higher in INSURE group $\{60 \%(n=30)$ vs. $30 \%(n=15), p<0.05\}$ as compared to LISA group. The duration of mechanical ventilation was also significantly higher in INSURE group with median 71 (IQR 62) vs. 40 (IQR 75) hours, p <0.05 as compared with LISA group. Duration of respiratory support (CPAP) was noted significantly $(p<0.05)$ greater in LISA group, having median of 48 hours (IQR 42) as compared with INSURE group median 29.5 hours (IQR 43). There was no significant $(p>0.05)$ difference in both groups with respect to final outcome. In LISA group, 31 (62\%) babies were discharged and 19 (38\%) died; and in INSURE group, $22(44 \%)$ discharged and $28(56 \%)$ died; but this difference was not statistically significant. Similarly, there was no significant $(p<0.05)$ difference in both groups on the basis of complications. Forty-one (82\%) newborns in LISA group and 38 (76\%) newborn babies in INSURE did not develop any complication.

The duration of hospital stay showed a similar trend in both groups with median hospital stay of 7 days(IQR 5) in LISA group and 6 days (IQR 4) in INSURE group, with $\mathrm{p}$-value of 0.304 as given in Table II.

Table II: Comparison of outcome between both groups.

\begin{tabular}{|c|c|c|c|}
\hline & LISA & INSURE & $p$-value \\
\hline $\begin{array}{l}\mathrm{FiO} 2 \text { reduction after the } \\
\text { procedure, median (IQR) }\end{array}$ & $30.0(30)$ & $25.0(10)$ & $0.031^{*} \S$ \\
\hline $\begin{array}{l}\text { Duration of respiratory } \\
\text { support CPAP in hours, } \\
\text { median (IQR) }\end{array}$ & $48.0(42)$ & $29.5(43)$ & $0.008^{* *} \S$ \\
\hline \multicolumn{4}{|l|}{$\begin{array}{l}\text { Invasive mechanical } \\
\text { ventilation needed, } \mathrm{n}(\%)\end{array}$} \\
\hline Yes n (\%) & $15(30 \%)$ & $30(60 \%)$ & $0.003^{* *}$ \\
\hline No n (\%) & $35(70 \%)$ & $20(40 \%)$ & \\
\hline $\begin{array}{l}\text { Duration of mechanical } \\
\text { ventilation in hours, } \\
\text { median (IQR) }\end{array}$ & $40.0(75)$ & $71.0(62)$ & $0.004{ }^{* *} \S$ \\
\hline $\begin{array}{l}\text { Hospital stay in days, } \\
\text { median (IQR) }\end{array}$ & $7.0(5)$ & $6.0(4)$ & $0.304 \S$ \\
\hline \multicolumn{4}{|l|}{ Final outcome: } \\
\hline Death, n (\%) & $19(38 \%)$ & $28(56 \%)$ & 0.071 \\
\hline Discharge, $\mathrm{n}(\%)$ & $31(62 \%)$ & $22(44 \%)$ & \\
\hline \multicolumn{4}{|l|}{ Complications: } \\
\hline Pneumothorax, n (\%) & $2(4 \%)$ & $5(10 \%)$ & 0.635 \\
\hline PDA, n (\%) & $3(6 \%)$ & $2(4 \%)$ & \\
\hline $\begin{array}{l}\text { Pulmonary } \\
\text { hemorrhage, n (\%) }\end{array}$ & $4(8 \%)$ & $5(10 \%)$ & \\
\hline No complications, n (\%) & $41(82 \%)$ & $38(76 \%)$ & \\
\hline
\end{tabular}

LISA $=$ Less invasive surfactant administration, INSURE=intubation surfactant administration and extubation, IQR=Interquartile range, $P D A=P$ atent ductus arteriosis.

* Significant at $5 \%$ level of significance.

** Significant at $1 \%$ level of significance.

$\S$ The variables didn't follow the normal distribution, so Mann Whitney U test was applied.

\section{DISCUSSION}

RDS is a serious lung condition in preterm infants. Surfactant use has led to decreased respiratory morbidity and mortality due to RDS.4,9,10 Nowadays, most preterm with RDS are treated initially with nCPAP, though certain number of neonates still need surfactant therapy to improve their respiratory outcomes. 10 In these infants, intubation is solely needed to administer surfactant into the lungs. INSURE is used as conventional method in most centers to provide surfactant therapy. LISA has been introduced as an alternative to this, but its influence on the overall neonatal outcome is yet to be evaluated.

LISA mainly depends on the spontaneous breathing effort of the preterm baby to distribute surfactant in lungs, instead of repeated positive pressure ventilation used during INSURE technique. This can avoid atelectasis associated even with brief intubation and ventilation. ${ }^{11-13}$ Feasibility, safety, and efficacy of various 
LISA techniques have been compared in prospective RCTs and observational trials with similar short term results compared with the standard approach.13,14 In the present study, all the patients received surfactant successfully. A second attempt of catheterization was needed in one patient only.

Various studies have demonstrated a positive outcome with LISA with regard to $\mathrm{FiO}_{2}$ reduction and ventilation. 14-16 It was observed significant reduction in $\mathrm{FiO}_{2}$ after the surfactant delivery (median 30\% IQR 30 vs. $25 \%$ IQR 10 in LISA and INSURE group, respectively). In contrast to the above findings, Ramos and colleagues showed nonsignificant difference between the LISA and standard groups, $73.3 \%$ vs. $86.6 \%{ }^{8}$

In this study, a significant difference was found in the need for mechanical ventilation as well as duration of ventilation between the two groups. In LISA group, there was significantly less need of ventilation, with significantly reduced number of days on ventilation. Similar results have been seen in other studies done previously. 8,14-16 Ramos-Navarro et al. observed significantly lower need of mechanical ventilation in LISA group $(43.3 \%)$, while it was $73 \%$ in control group and less need for $\mathrm{O}_{2}$ supplementation at 28 days, $30 \%$ vs. $45 \%$ with $p=0.031 .8$ In a German, AMV (avoiding mechanical ventilation) trial, infants of LISA group had significantly less days on ventilation, median 0 days, IQR 0-3, vs. 2 days, 0-5 days in the control group. ${ }^{17}$

Dargaville et al. used a 16-gauge semi-rigid vascular catheter instead of feeding tube for intratracheal catheterization, and reported a reduction in need of MV in first 72 hours in infants $25-28$ weeks GA $32 \%$ vs. $68 \%$ historical cohorts, $p$-value $=0.001$ and infants $29-34$ weeks $22 \%$ vs. $45 \%$ historical controls, $p=0.057 .7$ The results of German multicenter study revealed that in extremely premature (23-26 weeks gestation) infants in intervention group (LISA) had significantly less frequent intubation $(74.8 \%$ vs. $99 \%)$ and fewer days on mechanical ventilation as compared to control group. ${ }^{18} \mathrm{~A}$ Turkish study compared TAKE CARE procedure using 5Fr nasogastric catheter for tracheal catheterization with INSURE. The study revealed similar results with significantly shorter mean duration of CPAP and ventilation in TAKE CARE group; $p$-value 0.006 and 0.002 , respectively. ${ }^{16} \mathrm{~A}$ recent meta-analysis conducted at St.Barnabas Medical Center, NJ, USA also showed similar findings. ${ }^{19}$

In contrast, Mohammadizadeh et al. noted no difference in the need of mechanical ventilation between LISA and INSURE groups, but duration of ventilation was significantly shorter in the intervention group. 20 Aguar et al. also reported no significant difference in the need of mechanical ventilation $(25 \%$ vs. $33 \%, p=0.44)$, duration of MV (115 hours vs. 150 hours, $p>.05$ ), compared to using the INSURE technique. ${ }^{21}$
Canals Candela et al. found median CPAP days were 5.5 days in less invasive group, while it was 4 days in control group, $p=0.411 .15$ In this study, similar trend was also found in CPAP. Duration of CPAP was significantly greater in LISA group (median 48 hours, IQR 42) as compared with INSURE group (median 29.5 hours, IQR 43) which supports the observations made by Canal Candela et al. and Dargaville et al.15,22 There was overall reduction in nCPAP failure, reduced average days on mechanical ventilation, and reduced pneumothorax (from 8 to 2.4\%).22 Meta-analysis about LISA showed significant reduction in duration of nCPAP in LISA group (MD= -68.874 hours; $p<.001) .{ }^{19}$

In this study, improved survival ratio of babies was found in LISA group (62\% discharged, $38 \%$ died) as compared to INSURE group (44\% discharged, $56 \%$ died), without statistical significance. A recent meta-analysis did not show any significant difference in mortality or risk of complication between LISA or INSURE (RR=1.13; 95\% $\mathrm{Cl}=0.603, p=.691) .19$ No significant difference was observed in both groups on the basis of complication rate (pneumothorax, PDA, pulmonary hemorrhage). In INSURE group 5 patients (10\%) developed pneumothorax as compared to $2(4 \%)$ in LISA group $(p=0.625)$. This finding was also seen in previous studies. According to a meta-analysis of less invasive surfactant administration at St. Barnabas Medical Center, NJ, USA, few patients in LISA group developed pneumothorax as compared to INSURE group, $17.6 \%$ reduction but was not significant. 19 Kribs et al. had also observed less risk of pneumothorax and severe IVH in LISA group, survival without BPD was $67.3 \%$ vs. $58.7 \%(p=0.20) .{ }^{13}$

With the use of LISA technique, the outcome of the premature infants with RDS can be improved, reducing the cost of hospital stay and complications of mechanical ventilation by avoiding intubation.

\section{CONCLUSION}

Compared to INSURE, the LISA method has been found to be more effective in managing preterm babies with RDS along with nCPAP, and thereby preventing complications due to intubation and mechanical ventilation. This procedure can be performed even in level II NICU where the facility of nasal CPAP is available. In our healthcare system with limited resources, this method can be promising and effective step, which is feasible, cost-effective, and safe.

\section{REFERENCES}

1. Verder H, Bohlin K, Kamper J, Lindwal R, Jonssons B. Nasal CPAP and surfactant for treatment of respiratory distress syndrome and prevention of BPD. Acta Paediatrica 2009; 98:1400-8.

2. Dunn MS, Kaempf J, de Klerk A, de Klerk R, Reilly M, Howard D, et al. Vermont Oxford network DRM study group. Randomized 
trial comparing 3 approaches to the initial respiratory management of preterm neonates. Pediatrics 2011; 128: e1069-76.

3. Support Study Group of the Eunice Kennedy Shriver NICHD Neonatal Research Network. Early CPAP versus surfactant in extremely preterm infants. N Engl J Med 2010; 362:1970-9.

4. Stevens TP, Harrington EW, Blennow M, Soll R. Early surfactant administration with brief ventilation vs. selective surfactant and continued mechanical ventilation for preterm infants with or at risk for respiratory distress syndrome. Cochrane Database Syst Rev 2007; 4:CD003063.

5. Kribs A, Vierzig A, Hunseler C, Eifinger F, Welzing L, Stutzer $H$, et al. Early surfactant in spontaneously breathing with nCPAP in ELBW infants: a single centre four-year experience. Acta Paediatr 2008; 97:293-8

6. Dargaville PA, Aiyappan A, Cornelius A, Williams C, De Paoli AG. Preliminary evaluation of a new technique of minimally invasive surfactant therapy. Arch Dis Child Fetal Neonatal Ed 2011; 96:F243-8.

7. Dargaville PA, Aiyappan A, Kuschel CA, Kamlin CO, De Paoli AG, Carlin JB, et al. Minimally invasive therapy in preterm infants on continuous positive airway pressure. Arch Dis Child Fetal Neonatal Ed 2013; 98:F122-6.

8. Ramos-Navarro C, Sanchez-Luna M, Zeballos-Sarrato S, Gonzallez-Pacheco N. Less invasive beractant administration in preterm infants: A pilot study. Clinics (Sao Paulo) 2016; 71:128-34.

9. Polin RA, Carlo WA; Committee on Fetus and Newborn; American Academy of Pediatrics. Surfactant replacement therapy for preterm and term neonates with respiratory distress. Pediatrics 2014; 133:156-63.

10. Lopez E, Gascoin G, Flamant C, Merhi M, Tourneux P, Baud O, et al. Exogenous surfactant therapy in 2013: What is next? Who, when and how should we treat a new born infant in future? BMC Pediatr 2013; 13:165.

11. Klotz D, Procaro U, Fleck T, Fuchs H. European perspective on less invasive surfactant administration - a survey. Eur $J$ Pediatr 2017; 176:147-54.

12. Ali E, Abdel Wahed M, Alsalami Z, Abouseif H, Gottschalk T, Rabbani $\mathrm{R}$, et al. New modalities to deliver surfactant in premature infants: A systematic review and meta-analysis. J Matern Fetal Neonatal Med 2016; 29:3519-24.

13. Gopel W, Kribs A, Hartel C, Avenarius S, Teig N, Groneck P, et al. Less invasive surfactant administration is associated with improved pulmonary outcomes in spontaneously breathing preterm infants. Acta Paediatr 2015; 104:241-6.

14. Bao Y, Zhang G, Wu M, Ma L, Zhu J. A pilot study of less invasive surfactant in very preterm infants in a Chinese tertiary Centre. BMC Pediatr 2015; 15:21

15. Canal Candela FJ, Vizcaino Diaz C, Ferrandez Berenguer MJ, Serrano Robles MI, Vazquez Gomis C, Quiles Dura JL. Surfactant replacement therapy with a minimally invasive technique: Experience in a tertiary Hospital. An pediatr (Barc) 2016; 84:79-84.

16. Kanamaz HG, Erdeve O, Canpolat FE, Mutlu B, Dilmen U. Surfactant administration via thin catheter during spontaneous breathing: randomized controlled trial. Pediatrics 2013; 131:e502-09

17. Göpel W, Kribs A, Ziegler A, Laux R, Hoehn T, Wieg C, et al. Avoidance of mechanical ventilation by surfactant treatment of spontaneously breathing infants (AMV): An open label, randomized, controlled trial. Lancet 2011; 378:1627-34.

18. Kribs A, Roll C, Gopel W, Weig C, Groneck P, Laux R, et al. Non-intubated surfactant application vs. conventional therapy in extremely preterm infants: a randomized clinical trial. JAMA Pediatr 2015; 169:723-30.

19. Lau CSM, Chamberlain RS, Sun S. Less invasive surfactant administration reduces the need for mechanical ventilation in preterm infants: a meta-Analysis. Glob Pediatr Health 2017; 4:2333794X17696683.

20. Mohammadizadeh M, Ardestani AG, Sadeghnia AR. Early administration of surfactant via thin intratracheal catheter in preterm infants with respiratory distress syndrome: Feasibility and outcome. J Res Pharm Pract 2015; 4:31-6.

21. Aguar M, Cernada M, Brugada M, Gimeno A, Gutierrez A, Vento M. Minimally invasive surfactant therapy with a gastric tube is as effective as the intubation, surfactant, and extubation in preterm babies. Acta Paediatr 2014; 103:e229-33.

22. Dargaville PA, Ali SKM, Jackson HD, Williams C, De Paoli AG. Impact of minimally invasive surfactant therapy in preterm infants at 29-32 weeks gestation. Neonatology 2018; 113:7-14. 